\title{
Testicular growth, hormone concentrations, seminal characteristics and sexual behaviour in stallions
}

\author{
J. Naden, R. P. Amann and E. L. Squires \\ Animal Reproduction Laboratory, Colorado State University, Fort Collins, CO 80523, USA
}

\begin{abstract}
Summary. Puberty was studied using 15 colts of Quarter Horse phenotype. Total scrotal width was measured every 8 weeks from 48 to 96 weeks. Blood samples were taken from 8 colts at 8,16 and 24 weeks and then every 4 weeks until 100 weeks to measure changes in LH, FSH and testosterone concentrations. Seminal collections were attempted monthly from 48 to 64 weeks and every 2 weeks thereafter until puberty, and resumed every 3 rd day from 96 weeks for 15 ejaculates. For all collections, times to erection, mount and ejaculation and seminal characteristics were recorded. Age at puberty was defined as the first ejaculate containing $50 \times 10^{6}$ spermatozoa, with $\geq 10 \%$ motile. Colts were castrated at 2 years to enable determination of daily sperm production (DSP), epididymal sperm reserves and normality of spermatogenesis. Total scrotal width increased linearly from 48 to 96 weeks. Age at puberty averaged 83 weeks (56-97 weeks). Changes in serum concentrations of LH and FSH were parallel, rising at 36-40 weeks, declining after 40 weeks and rising again at $68-80$ weeks. Testosterone was low until 68 weeks after which concentrations rose slowly to 80 weeks and increased rapidly to a plateau at 92 weeks. Sexual behaviour and seminal characteristics differed $(P<0.05)$ between puberty and 2 years, except for time to erection, time to mount, and percentage of motile spermatozoa. DSP at 2 years averaged $1.7 \times 10^{9}$ and daily sperm output (DSO) averaged $1.1 \times 10^{9}$. The correlation between DSP and DSO was $0.83(P<0.01)$. There were $9.57 \times 10^{9}$ spermatozoa/epididymis of which $67 \%$ were in the cauda.
\end{abstract}

Keywords: puberty; hormonal changes; stallions; testes; semen; sexual behaviour

\section{Introduction}

There has been no systematic study of puberty in the colt examining hormonal changes, testicular development and age at puberty. Classic data on testicular development in horses were interpreted (Nishikawa, 1959) as evidence that puberty occurs between 17 and $>22$ months in Anglo-Norman stallions, and Glassneck (1978) noted a great difference in testicular development among warmblood colts of similar age, but made no conclusions regarding age at puberty. Puberty, as determined by seminal characteristics, occurred between 11.5 and 14.5 months in Welsh pony stallions (Skinner \& Bowen, 1968) and between 12 and 23.6 months in Quarter Horse colts (Cornwell, 1972).

Wesson \& Ginther (1980) studied gonadotrophin concentrations in blood plasma from colts between birth and 8 months; however, it is unlikely that endocrine changes prerequisite for puberty would have been detected. Thompson \& Honey (1984) measured changes in LH, FSH, and testosterone values in colts from 6 to 26 months of age, but age at puberty was not determined.

Knowledge of the normal progression of events before and after puberty is necessary if further research is to be conducted on puberty in the horse. The objectives of this study were to: (1) characterize age-associated changes in testicular size and blood concentrations of $\mathrm{LH}, \mathrm{FSH}$, and testosterone; (2) determine age at puberty; (3) characterize seminal characteristics and sexual 
behaviour at 2 years; and (4) evaluate daily sperm production, epididymal sperm reserves, and normality of spermatogenesis at 2 years of age.

\section{Materials and Methods}

General. Fifteen cross-bred, light horse colts, born between $10 \mathrm{July}$ and 3 September 1985 (all but 2 born before 13 August) were used. The colts were part of a study to determine effects on offspring of administering an oral progestagen (Regu-Mate: Hoechst-Rousse! Agri-Vet Company, Somerville, NJ, USA) to pregnant mares. There was no significant effect of prenatal treatment on any reproductive characteristic of the colts (relative to control colts; data not shown), so all data reported herein was pooled across treatment. Foals were maintained on pasture with their dams, and had access to a limited amount of creep feed, until weaned at 16-20 weeks of age. Thereafter, colts received alfalfa hay ad libitum, and a measured daily ration of grain which was formulated to meet $100 \% \mathrm{NRC}$ requirements for weanling and growing horses (Lewis, 1982). Colts were together in an outdoor paddock until approximately 64 weeks, after which they were housed in individual pens $(12.2 \times 3.7 \mathrm{~m})$ with shade until castrated at 2 years of age.

Testicular size. Total scrotal width (TSW) was measured (Gebauer et al., 1974b) every 8 weeks from 48 to 96 weeks of age by 2 technicians (triplicate measurements by each). The arithmetic mean of these 6 measurements was used for statistical analyses.

Hormone analyses. Eight colts were randomly selected to monitor the age-associated changes in serum concentrations of LH, FSH and testosterone. They were born between 20 July and 29 August. Three blood samples were taken in the morning by jugular venepuncture at $1-\mathrm{h}$ intervals at 8,16 and 24 weeks and every 4 weeks thereafter. Samples were allowed to clot at ambient temperature for $1 \mathrm{~h}$, and then stored overnight at $5^{\circ} \mathrm{C}$. Equal volumes of serum from the 3 samples were pooled for each stallion, to give I 'monthly' sample which was stored at $-20^{\circ} \mathrm{C}$ until analysed. Each sample was assayed for LH (Nett et al., 1975), FSH (Nett et al., 1979) and testosterone (Berndtson et al, 1974) using procedures validated for horse blood serum. Lower limits of sensitivity were $0.60,5.35$ and $0.01 \mathrm{ng} / \mathrm{ml}$ for the LH, FSH and testosterone assays respectively. All samples were run in 1 assay: intra-assay variations were 7.9 , 11.7 and $6.8 \%$ for the $\mathrm{LH}, \mathrm{FSH}$ and testosterone assays respectively.

Seminal characteristics. Puberty was defined as the age when the first ejaculate was obtained containing a minimum of $50 \times 10^{6}$ spermatozoa with $\geq 10 \%$ progressively motile (Wolf et al., 1965). Seminal collections by artificial vagina (Pickett et al., 1987) were attempted every 4 weeks from 48 to 64 weeks and every 2 weeks thereafter. Once puberty was achieved, 4 more samples were collected, at 2-week intervals, to ensure that the criteria were met consistently. Seminal collections resumed at 96 weeks and continued every 3 days until 15 ejaculates had been collected near 2 years of age.

Volumes of gel and gel-free semen, concentration of spermatozoa/ml gel-free semen, and $\mathrm{pH}$ were measured (Pickett et al., 1987) and total spermatozoa per ejaculate was calculated. Because there was no significant decline in total sperm number per ejaculate associated with day of collection after Week 96, data for all 15 ejaculates were used to calculate mean daily sperm output for each stallion. Percentage of progressively motile spermatozoa at $37^{\circ} \mathrm{C}$ was determined at $\times 200$ using a phase-contrast microscope. Percentages of morphologically normal spermatozoa were determined for the pubertal ejaculate and for Ejaculates 3, 6, 9, 12 and 15 collected after Week 96. Seminal smears were stained with Hancock's stain (Hancock, 1952; Pickett \& Back, 1973) and 200 cells/ejaculate were evaluated by 1 technician.

Sexual behaviour. For each attempted seminal collection, colts were exposed to an oestrous mare of appropriate size for a maximum of $20 \mathrm{~min}$. Sexual behaviour was assessed (Clay et al., 1987) by timing the intervals to: (1) erection, (2) first mount with erection and intromission, and (3) ejaculation. Number of mounts per ejaculate also was recorded.

Daily sperm production and epididymal sperm reserves. Colts were anaesthetized and bilaterally castrated the day after the last seminal collection. Testes and epididymides were trimmed and weighed; testicular size was measured. The tunica albuginea was weighed, and weight of testicular parenchyma calculated by difference. Epididymides and a weighed sample of testicular parenchyma $(6-12 \mathrm{~g})$ were stored at $-20^{\circ} \mathrm{C}$.

One testis and epididymis was randomly chosen from each stallion for detailed evaluation, except for 4 stallions who had both testes and epididymides evaluated ( 2 normal and 2 which had 1 small testis). After thawing, tissues (testicular parenchyma; caput, corpus, or cauda epididymidis) were homogenized (Amann et al., 1979) using a known quantity of an aqueous solution containing $150 \mathrm{~mm}-\mathrm{NaCl}, 3.9 \mathrm{~mm}-\mathrm{NaN}_{3}$ and $0.05 \%(\mathrm{v} / \mathrm{v})$ Triton X-100. Cytometer counts of homogenization-resistant, elongated spermatids or spermatozoa were made by 4 technicians each counting 2 chambers. The mean of the 8 counts was used to calculate number of spermatids/g testis, and per testis, or number of spermatozoa per epididymal region. To calculate daily sperm production (DSP), the number of spermatids in testicular tissue was divided by 6.00 days (Amann et al., 1976). The transit time of spermatozoa through each segment of the epididymis was determined by dividing the number of spermatozoa within that segment by the DSP of the testis providing those spermatozoa (Amann et al., 1976).

For histological evaluations, tissue from a randomly selected locus in each testis was fixed in Bouin-Hollande fluid and embedded in Paraplast. Tissue was sectioned at $5 \mu \mathrm{m}$ and stained by the periodic acid-Schiff technique and counterstained with haematoxylin. Sections evaluated were from the same testis evaluated for DSP. Spermatogenesis 
was assessed by counting the numbers of nuclei of A-spermatogonia, young (leptotene) and old (pachytene) primary spermatocytes, spherical spermatids and Sertoli cells (with a visible nucleolus) contained in each of 20 randomly selected stage I seminiferous tubules (Berndtson et al., 1983). Five randomly chosen nuclei (nucleoli for Sertoli cells) of each cell type were measured per testis, and the mean was calculated. Data for numbers of germ cells were corrected for section thickness and nuclear diameter (Abercrombie, 1946) and results were expressed on a per Sertoli cell basis (Clermont \& Morgentaler, 1955) to compensate for differences in diameter of the seminiferous tubules.

Data for 2 stallions were excluded from statistical analysis of testicular histology because the tubules were not typical of a normal testis; many tubules contained few germ cells. Both stallions had reached puberty only 5 weeks before castration.

Statistical analyses. Analyses of variance were used to determine age-associated differences in testicular size, hormone concentrations, sexual behaviour and seminal characteristics, and to analyse for potential differences in sexual behaviour and seminal characteristics within and between ejaculates at 2 years of age. If the F-test was significant $(=0.05)$, means were separated using the Student-Neuman-Keul's procedure (Steel \& Torrie, 1980). Regression analysis was used to describe testicular growth and effect of interval after puberty on DSP/g of testis.

\section{Results and Discussion}

\section{Age at puberty}

The average age at puberty was 83 weeks \pm 2.9 weeks, and ranged from 56 to 97 weeks. Of 15 colts, 12 attained puberty by 90 weeks of age. Age at puberty was similar to that reported by Cornwell (1972) for 23 spring-born Quarter Horse colts (69 weeks, range 55-101 weeks), but greater than values reported by Skinner \& Bowen (1968) for Welsh ponies (about 55 weeks). Stallions born in March or April probably would not attain puberty at a younger age than colts in this study, since photoperiodic cues involved in timing seasonal cyclicity (Clay et al., 1987) probably are subordinate to other factors. Although 7 of the 15 colts attained puberty in JanuaryMarch, and 6 in April-June, 2 colts attained puberty in September and November, at 56 and 68 weeks of age. Therefore, season of birth probably has little effect on age at puberty in stallions and the discrepancy with data reported by Skinner \& Bowen (1968) may be due to other factors such as small sample size, criteria used to determine puberty, level of nutrition, and breed differences.

Two colts were 'shy' and reluctant to serve the artificial vagina. It was suspected that they had sufficient testicular activity to produce a 'pubertal' ejaculate before they actually did (at 85 and 90 weeks). The first ejaculates produced by these colts contained $>1.8 \times 10^{9}$ spermatozoa and $\geq 35 \%$ progressively motile spermatozoa. Exclusion of these colts gave an average age at puberty of 82 weeks. These 2 colts were excluded from all calculations involving interval after puberty.

\section{Testicular growth}

Total scrotal width increased linearly $(P<0.01)$ from 48 to 88 weeks of age (Fig. 1). The increase with age was described by the equation $y=2.89+0.89 \mathrm{~A}(r=0.82)$ where $y$ is total scrotal width in $\mathrm{mm}$ and $\mathrm{A}$ is age in weeks. There was no significant difference between total scrotal width at 88 and 96 weeks, May-July $(P>0.05)$. Total scrotal width differed between each successive pair of ages $(P<0 \cdot 05)$. Testicular growth continues past 5 years of age in stallions (Nishikawa, 1959; Thompson et al., 1979; Johnson \& Thompson, 1983). Adult stallions experiencing ambient daylength had maximal total scrotal width in June and July, and then testicular regression began (Clay et al., 1987). Since the colts were 96 weeks old in June or July, the apparent plateau of testicular growth between 88 and 96 weeks was probably the first of several annual cessations of testicular growth or development (Pickett et al., 1989).

If total scrotal width had been measured from an earlier age, a curvilinear testicular growth pattern would presumably have been detected, similar to that reported for bulls (Curtis \& Amann, 1981). Nishikawa (1959) reported little testicular growth from birth to 10 months, slow gowth from 11 to 16 months and rapid growth after 17 months in the stallion. Our measurements probably focussed on the rapid growth phase. 


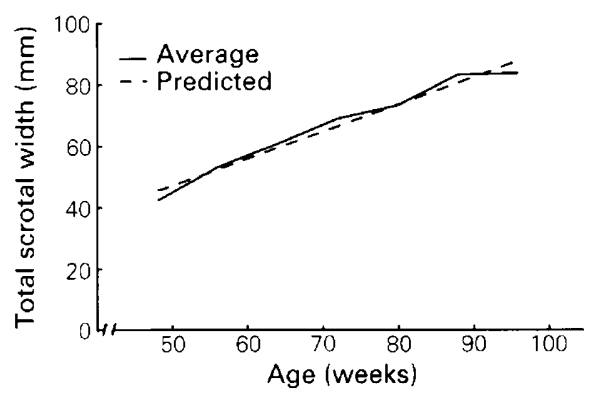

Fig. 1. Average total scrotal width $(\mathrm{N}=15)$ and predicted total scrotal width in colts from 48 to 96 weeks of age.

\section{Hormonal changes}

Concentrations of $\mathrm{LH}$ in serum were low from 8 to 32 weeks, elevated at 36-40 weeks, declined steadily until 60 weeks, and remained low until 80 weeks (Fig. 2). Concentrations of FSH were more variable than those of $\mathrm{LH}$, and generally followed a similar trend although there was a steady increase after 64 weeks of age.

Testosterone was undetectable in serum from 8 to 28 weeks of age. Testosterone first was detected at 32 weeks $(0.03 \mathrm{ng} / \mathrm{ml})$ and increased in concentration through 56 weeks $(0.040 .06 \mathrm{ng} /$ $\mathrm{ml}$ ). This rise in testosterone occurred after that of LH. Testosterone concentrations declined after about 60 weeks, but a dramatic increase then appeared at 75-80 weeks (Fig. 2).

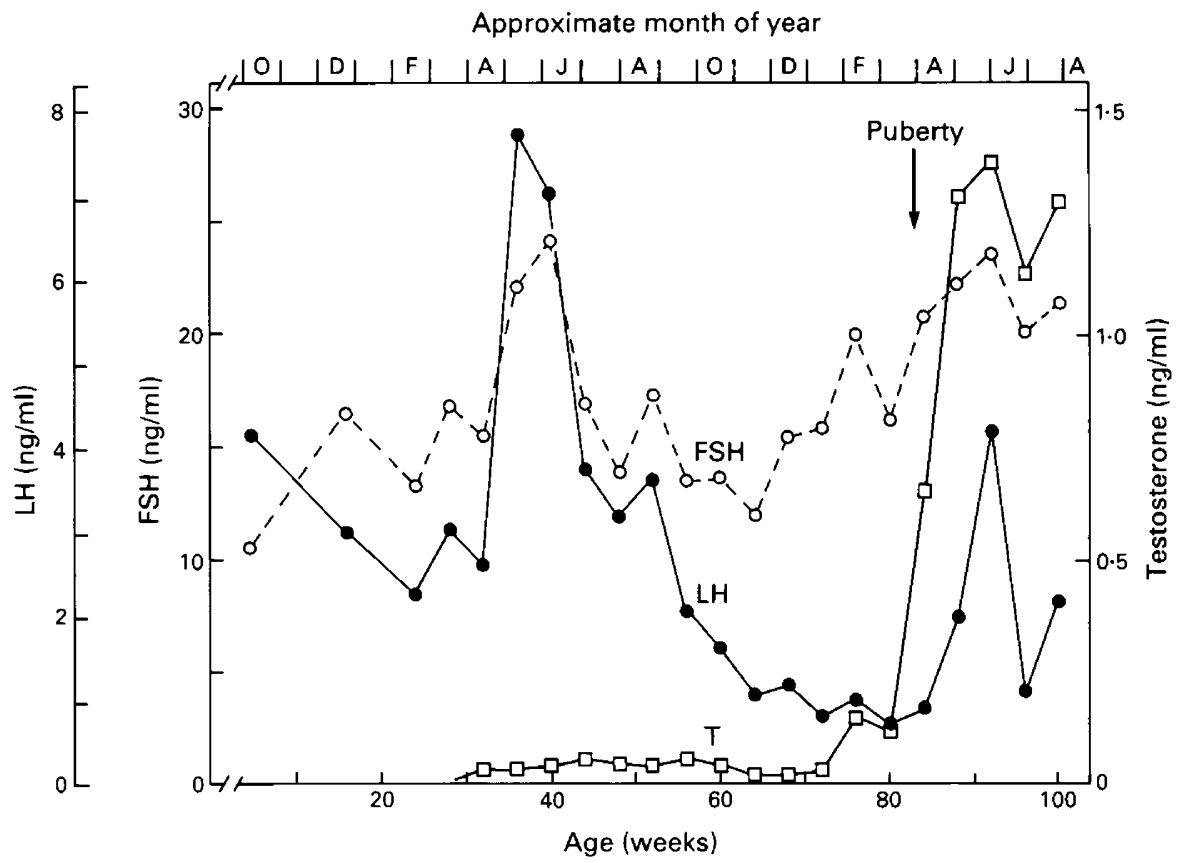

Fig. 2. Age associated changes in serum concentrations of LH, FSH and testosterone in colts from 8 to 100 weeks of age $(\mathrm{N}=8)$.

Since puberty occurred at 83 weeks, and spermatogenesis takes 57 days in stallions (Pickett et al., 1989), spermatogenesis was initiated before 73 weeks of age on the average, and as early as 46 weeks in at least 1 stallion. Therefore, the increase in testosterone concentration starting after 72 
weeks was coincident with the oldest age at which spermatogenesis could have started. However, because of the great dilution of testosterone in testicular venous blood upon entering the systemic circulation (Ganjam \& Amann, 1973), the concentration of testosterone in the testes may have increased and been sufficient for spermatogenesis before an increase in peripheral concentrations occurred at 72 weeks of age.

Patterns of LH and testosterone concentrations in these stallions (Fig. 2) were similar to those of colts (Thompson \& Honey, 1984), ram lambs (Olster \& Foster, 1986), bulls (McCarthy et al., 1979; Amann \& Walker, 1983), and boars (Florcruz \& Lapwood, 1978). The characteristic pattern in all species is that $\mathrm{LH}$ is low from birth, but has an early initial peak. A rise in testosterone was not coincident with the initial increase in $\mathrm{LH}$ secretion, which suggests that Leydig cells initially are unable to respond to $\mathrm{LH}$ by secreting testosterone. This rise in $\mathrm{LH}$ is postulated to stimulate Leydig cells to begin testosterone production (Amann \& Walker, 1983), but the initial response may be suppressed by seasonality in stallions.

The decline of $\mathrm{LH}$, as well as the time before testosterone concentrations increased significantly appeared to be more prolonged in pubertal stallions than in rams or bulls. Seasonal effects may have prolonged the time required to increase $\mathrm{LH}$ and testosterone concentrations. The winter months (September-January) for these colts were from $\sim 52$ to 72 weeks of age. Clay et al. (1988) reported that seasonal fluctuations in serum $\mathrm{LH}, \mathrm{FSH}$ and testosterone concentrations in stallions resulted in low hormone values in September-January. Presumably, seasonal inhibition of gonadotrophin and testosterone secretion may have influenced hormone profiles observed for these colts. Further research is needed to address the effects of season of birth on ontogeny of $\mathrm{LH}$ and testosterone secretion in stallions.

FSH secretion in these colts was similar to that reported for spring-born colts (Thompson \& Honey, 1984) and rams (Olster \& Foster, 1986) with FSH concentrations declining concomitantly with $\mathrm{LH}$ and rising a second time before the increase in testosterone. However, FSH concentrations changed little from birth to 8-10 months in bulls (McCarthy et al., 1979; Amann \& Walker, 1983). FSH secretion therefore appears to approximate changes in LH secretion in the ram and stallion, but is different from the pattern of LH secretion in bulls.

\section{Seminal characteristics}

Seminal characteristics for the pubertal ejaculate and the average for the last 15 ejaculates at 2 years differed $(P<0.05)$, except for percentage of progressively motile spermatozoa (Table 1$)$. The average pubertal ejaculate contained only $1 \cdot 14 \times 10^{9}$ spermatozoa, but $26 \%$ were progressively motile. Studies with bull calves showed that percentage of motile spermatozoa increased for 12 to 16 weeks after puberty (Almquist \& Amann, 1976; Lunstra \& Echternkamp, 1982), after which normal percentages of motile spermatozoa were attained. At 96 weeks, the average stallion was 13 weeks after puberty. Possibly stallions require a longer post-pubertal interval for attainment of $50 \%$ progressively motile spermatozoa than do bulls, or this group of stallions had reached their adult quality but the subjective observations were unusually harsh.

As expected, seminal volumes and sperm numbers at 2 years were much lower than values reported for adult stallions (Gebauer et al., 1974a; Pickett et al., 1976). Nevertheless, total spermatozoa/ejaculate increased 3-fold between puberty and 2 years of age. Mean DSO was $1.1 \times 10^{9}$ (range $0.25-3.37 \times 10^{9}$ ), which is much less than the $7.0 \times 10^{9}$ reported for adult stallions (Gebauer et al., 1974a; Clay et al., 1987).

Total spermatozoa per ejaculate differed $(P<0.05)$ among stallions, but variance associated with ejaculates within stallions was not significant $(P>0.05)$.

\section{Sexual behaviour}

Data for sexual behaviour represented all 15 colts at puberty, but only 12 at 2 years. Data for 3 stallions at 2 years were excluded because they had poor libido and required special management 
Table 1. Seminal characteristics and sexual behaviour of colts at puberty and 2 years

\begin{tabular}{|c|c|c|}
\hline & Puberty & 2 years \\
\hline \multicolumn{3}{|l|}{ Seminal characteristics } \\
\hline Gel volume (ml) & $0.4 \pm 0.2$ & $2 \cdot 3 \pm 0 \cdot 3^{*}$ \\
\hline Gel-free volume $(\mathrm{ml})$ & $12 \cdot 1 \pm 2 \cdot 5$ & $20 \cdot 9 \pm 2 \cdot 6^{*}$ \\
\hline Total volume $(\mathrm{ml})$ & $12 \cdot 5 \pm 2.5$ & $23 \cdot 2 \pm 2 \cdot 7^{*}$ \\
\hline Sperm conc. $\left(\times 10^{-6}\right)$ & $99.0 \pm 16.8$ & $161 \cdot 0 \pm 20 \cdot 5^{*}$ \\
\hline $\begin{array}{l}\text { Total spermatozoa } \\
\left(\times 10^{-9}\right)\end{array}$ & $1 \cdot 1 \pm 0 \cdot 3$ & $3 \cdot 3 \pm 0 \cdot 7^{*}$ \\
\hline $\begin{array}{l}\text { Progressively motile } \\
\text { spermatozoa }(\%)\end{array}$ & $26 \cdot 0 \pm 2 \cdot 8$ & $26 \cdot 0 \pm 4 \cdot 5$ \\
\hline $\mathrm{pH}$ & & $7.5 \pm 0.0$ \\
\hline Normal spermatozoa $(\%)$ & $33.0 \pm 3.8$ & $44 \cdot 0 \pm 2 \cdot 8^{*}$ \\
\hline \multicolumn{3}{|l|}{ Sexual behaviour } \\
\hline Time to erection $(\mathrm{min})$ & $3 \cdot 4 \pm 1 \cdot 0$ & $1.6 \pm 0.5$ \\
\hline Time to 1 st mount (min) & $4 \cdot 4 \pm 1 \cdot 1$ & $1.9 \pm 0.5$ \\
\hline Time to ejaculation (min) & $7 \cdot 3 \pm 1 \cdot 4$ & $3.4 \pm 0.5^{*}$ \\
\hline Total no. of mounts & $2 \cdot 5 \pm 0.3$ & $1.6 \pm 0.1^{*}$ \\
\hline
\end{tabular}

Values are mean \pm s.e.m. for 15 colts except for sexual behaviour at 2 years when $\mathrm{N}=12$.

$* P<0.05$.

and stimulation (extensive time in a 'hot box'; Pickett et al., 1987) to permit seminal collection. There was no significant difference $(P>0.05)$ between the times for first erection and first mount (Table 1) at puberty and 2 years of age. However, time to ejaculation and total number of mounts required for ejaculation (Table 1$)$ were less $(P<0.05)$ at 2 years of age. Presumably, the decrease in ejaculation time and number of mounts at 2 years was due to a combination of age and experience. Total time to ejaculation and total number of mounts per ejaculation at 2 years were similar to those for adult stallions (Pickett et al., 1976).

There was no difference $(P>0.05)$ for any of the sexual behaviours at 2 years when data for Ejaculates 1-5, 6-10 and 11-15 were compared.

\section{Testicular characteristics}

There was no difference $(P>0.05)$ between the left and right testes or epididymides for any weight or size measurement. Therefore, averages for both testes are presented (Table 2). However, Nishikawa (1959) and Gebauer et al. (1974b) reported tendencies for the left to be larger than the right testis and that was true of these data (107 vs $100 \mathrm{~g}$ ). Nishikawa (1959) concluded that the left testis developed earlier and grew more rapidly between 1 month to 4.5 years in $80 \%$ of stallions.

Table 2. Mean \pm s.e.m. tissue weights and dimensions of 15 colts at 2 years of age

\begin{tabular}{lrcr}
\hline Tissue & Left & Right & Average \\
\hline Testis & & & \\
Weight (g) & $106 \cdot 1 \pm 9 \cdot 5$ & $99 \cdot 9 \pm 8 \cdot 5$ & $103 \cdot 0 \pm 6 \cdot 3$ \\
Length (mm) & $77 \cdot 1 \pm 1 \cdot 8$ & $81 \cdot 2 \pm 2 \cdot 0$ & $79 \cdot 2 \pm 1 \cdot 4$ \\
Height (nm) & $48 \cdot 9 \pm 1 \cdot 7$ & $48 \cdot 5 \pm 2 \cdot 0$ & $48 \cdot 7 \pm 1 \cdot 3$ \\
Width (mm) & $46 \cdot 3 \pm 1 \cdot 6$ & $46 \cdot 3 \pm 1 \cdot 8$ & $46 \cdot 3 \pm 1 \cdot 1$ \\
Parenchyma (g) & $95 \cdot 2 \pm 8 \cdot 8$ & $89 \cdot 5 \pm 8 \cdot 1$ & $92 \cdot 4 \pm 5 \cdot 9$ \\
Epididymis (g) & $22 \cdot 2 \pm 1 \cdot 1$ & $20 \cdot 9 \pm 1 \cdot 1$ & $21 \cdot 5 \pm 1 \cdot 5$ \\
\hline
\end{tabular}




\section{Daily sperm production (DSP)}

The DSP/stallion and DSP/g testicular parenchyma averaged $1.70 \times 10^{9}\left(\right.$ range $\left.0.93-3.63 \times 10^{9}\right)$ and $9.18 \times 10^{6}$ (range $6.23-17 \cdot 22 \times 10^{6}$ ). Because the interval from puberty to castration at 2 years ranged from 5 to 45 weeks, data on efficiency of sperm production (DSP $/ \mathrm{g}$ ) were considered on this basis (Fig. 3). Even by 24-45 weeks after puberty, DSP/g averaged only $11 \times 10^{6}(\mathrm{~N}=4)$ as compared to $17-19 \times 10^{6}$ in adult stallions (Pickett et al., 1989). There was a linear relationship between DSP/g and interval after puberty (Fig. 3) which was described by the equation $y=6.34+$ $0 \cdot 11 \mathrm{~A}(r=0.70)$ where $y$ is $\mathrm{DSP} / \mathrm{g}\left(10^{6}\right)$ and $\mathrm{A}$ is the interval from puberty in weeks. Attainment of adult levels of DSP/stallion must involve a further increase of DSP $/ \mathrm{g}$ plus considerable growth of the testes. The interval after puberty was highly correlated $(P<0.01)$ to DSP $(r=0.86)$, DSO $(r=0 \cdot 90)$, testicular weight $(r=0 \cdot 72)$ and epididymal sperm reserves $(r=0 \cdot 86)$.

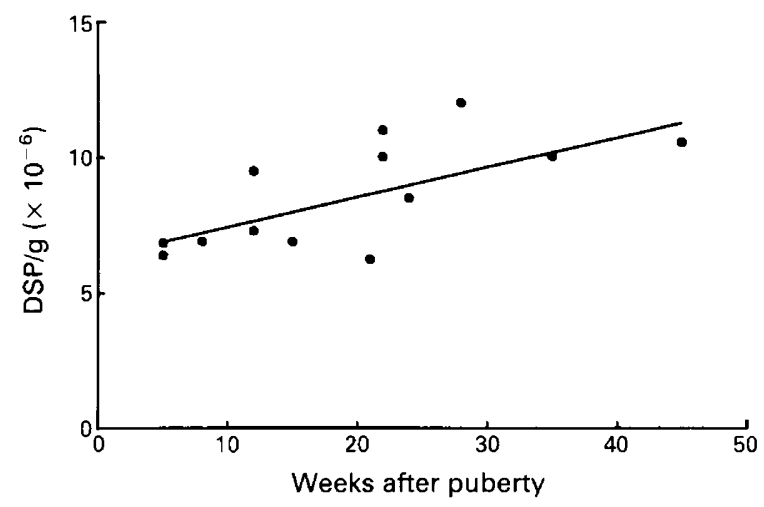

Fig. 3. Efficiency of sperm production, expressed as DSP/g testicular parenchyma, for colts castrated between 5 and 45 weeks after puberty. The line of best fit is shown.

Holstein bulls attain their mature efficiency of sperm production by 10-20 weeks after puberty (12-15 months of age; MacMillan \& Hafs, 1968; Killian \& Amann, 1972) and so increases in sperm production after 12-15 months are due solely to increased testicular weight. In stallions, however, $\mathrm{DSP} / \mathrm{g}$ or efficiency of spermatogenesis had not reached adult sperm production rates by 19 weeks after puberty. Although further research is needed to determine when adult DSP/g is achieved, it probably is not until the second breeding season following puberty.

The correlation between DSP and DSO was $0.83(P<0.01)$; therefore, DSP accounted for $69 \%$ of the variation in DSO. A similar correlation of $0.80(P<0.01)$ was reported for adult stallions (Gebauer et al., 1974a). The correlation between DSP and testis weight was $0.76(P<0.01)$ which is similar to the value of $0.77(P<0.01)$ reported for adult stallions (Gebauer et al., 1974b). DSO and testis weight were correlated $(r=0.86 ; P<0.01)$, as they are in dairy bulls $(r=0.82$; Amann \& Almquist, 1962).

\section{Epididymal sperm reserves}

The caput, corpus and cauda epididymidis contained $1.51,1.57$ and $6.49 \times 10^{9}$ spermatozoa (per side) respectively. These values were much lower than those for 5-9-year-old stallions $(5 \cdot 0$, 7.8 and 25.8 respectively; Amann et al., 1979) and this is consistent with the small size of the epididymides and testes of 2-year-old stallions. The cauda epididymidis contained $68 \%$ of the spermatozoa in the epididymis which is similar to $67 \%$ reported for 5-9-year-old stallions (Amann et al., 1979). For the 7 stallions castrated $\geq 20$ weeks after puberty, transit time of spermatozoa through the caput, corpus and cauda epididymidis averaged 1.6, 1.6 and 7.5 days respectively. 
Transit time through both the caput and corpus epididymidis ( 3.6 days) was similar to values reported for adult stallions at sexual rest ( $4 \cdot 0$ days), while transit time through the cauda epididymidis ( 7.5 days) was less than the 9.8 days reported for adult, sexually rested stallions (Amann, 1981). This difference was presumably because the colts had not been sexually rested before castration.

\section{Histology}

Counts of Sertoli cells and germ gells in Stage I seminiferous tubules revealed that there were $0.21,1.47,1.49$ and 5.09 A-spermatogonia, leptotene spermatocytes, pachytene spermatocytes and spherical spermatids per Sertoli cell. The value of 0.21 A-spermatogonia per Sertoli cell is similar to the value of 0.29 for adult stallions in the breeding season (Johnson \& Tatum, 1988). Nuclear diameter averaged $10 \cdot 1,7.8,9.6$ and $6.5 \mu \mathrm{m}$ for A-spermatogonia, leptotene spermatocytes, pachytene spermatocytes and spherical spermatids, respectively. For each A-spermatogonium, there were 7.6 leptotene spermatocytes. The ratio of leptotene to pachytene spermatocytes was $1: 1.02$ and of pachytene spermatocytes to spherical spermatids was $1: 3 \cdot 4$. Thus, as in adult stallions (Pickett et al., 1989) there was little degeneration of primary spermatocytes during prophase of meiosis when compared with the theoretical values of $1: 1$ leptotene to pachytene spermatocytes and 1:4 pachytene spermatocytes to spherical spermatids (Clermont, 1972).

\section{Temporal relationship among events associated with the onset of puberty}

The infantile period, which is marked by low gonadotrophin concentrations and little gonadal activity, appears to last about 32 weeks after birth in the colt. The beginning of the prepubertal period is marked by changes in the hypothalamic-pituitary axis which result in increased amounts of LH and FSH secretion between 32 and 40 weeks (Fig. 2). The prepubertal rise in LH secretion has been shown to be a result of increased LH pulse frequency in bulls (Amann \& Walker, 1983) and rams (Foster et al., 1978). Stallions presumably experience a similar change in frequency of LH secretion during the prepubertal period.

Surprisingly, secretion of $\mathrm{LH}$ at rates sufficient to provide $4-8 \mathrm{ng} / \mathrm{ml}$ serum before 1 year of age, did not result in a marked increase of testosterone secretion (Fig. 2). Probably this was because the blood concentration of $\mathrm{LH}$ between 30 and 59 weeks of age was much lower than that for adult stallions in the breeding season $(20-45 \mathrm{ng} / \mathrm{ml}$; Clay et al., 1988). Nevertheless, the next year, at $\geq 80$ weeks, secretion of testosterone was evident despite somewhat lower concentrations of LH. Amann \& Walker (1983) postulated that high concentrations of LH prepubertally induced differentiation of Leydig cells, enabling secretion of the testosterone necessary for normal Sertoli cell function and initiation of spermatogenesis.

LH and FSH concentrations were suppressed to a lower level after 40 weeks, presumably due to the negative feedback effect of testosterone on the hypothalamus and anterior pituitary. FSH concentrations began to rise again at 64 weeks, but $\mathrm{LH}$ values remained suppressed until 80 weeks of age. LH and FSH secretion therefore appear to be differentially controlled at this age.

Testosterone concentrations began to increase drastically after 72 weeks of age. This was coincident with the average age at which spermatogenesis would have had to begin to result in puberty at 83 weeks of age. Release of sufficient spermatozoa from the seminiferous tubules to permit attainment of puberty marks the end of the prepubertal period. The prepubertal period was also characterized by rapid, linear testicular growth (Fig. 1). Testicular growth rate slowed after puberty was attained. Presumably, testicular growth would have been slow during the infantile period, before measurements were made, resulting in a sigmoidal shaped growth curve.

Although efficiency of sperm production increased linearly from puberty to 2 years (Fig. 3), adult efficiency of sperm production was not achieved. Percentage progressively motile spermatozoa did not improve from puberty to 2 years, suggesting that the attainment of adult levels of sperm motility may take longer in stallions than other species. Sexual behaviour, as assessed by time to 
ejaculation and total number of mounts required for ejaculation, were similar to adult levels by 2 years. It therefore appears that different aspects of reproductive development in stallions require different intervals to reach adult levels. Hormonal changes are, presumably, the driving factor in the attainment of puberty. More research is necessary to determine how factors such as breed, level of nutrition and season of birth affect the temporal relationships between hormonal changes and the attainment of puberty in stallions.

We thank Dr R. K. Shideler and Dr A. O. McKinnon for attention to the medical needs of the animals in this study; W. E. Berndtson for histological evaluations; M. E. Crowder-Sousa and T. K. Pope for technical assistance with radioimmunoassays; G. J. Wiepz for graphics; and V. M. Cook and the numerous graduate and undergraduate students who made completion of this project possible.

Supported in part by Hoechst-Roussel Agri-Vet Company, Somerville, NJ; Pattridge Family Scholarship Fund, Golden, CO; and CSU Experiment Station.

\section{References}

Abercrombie, M. (1946) Estimation of nuclear population from microtome sections. Anat. Rec. 94, 239-247.

Almquist, J.O. \& Amann, R.P. (1976) Reproductive capacity of dairy bulls. XI. Puberal characteristics and postpuberal changes in production of semen and sexual activity of Holstein bulls ejaculated frequently. J. Dairy $S_{\text {(i. 59, 986-991. }}$

Amann, R.P. (1981) A critical review of methods for evaluation of spermatogenesis from seminal characteristics. J. Androl. 2, 37-58.

Amann, R.P. \& Almquist, J.P. (1962) Reproductive capacity of dairy bulls. VIII. Direct and indirect measurement of testicular sperm production. J. Dairy Sci. 45, 774-781.

Amann, R.P. \& Walker, O.A. (1983) Changes in the pituitary gonadal axis associated with puberty in Holstein bulls. J. Anim. Sci. 57, 433-442.

Amann, R.P., Johnson, L., Thompson, D.L., Jr \& Pickett, B.W. (1976) Daily spermatozoal production, epididymal spermatozoal reserves and transit time of spermatozoa through the epididymis of the Rhesus monkey. Biol. Reprod. 15, 586-592.

Amann, R.P., Thompson, D.L., Jr, Squires, E.L. \& Pickett, B.W. (1979) Effects of age and frequency of ejaculation on sperm production and extragonadal sperm reserves in stallions. J. Reprod. Fert., Suppl. 27, $1-6$.

Berndtson, W.E., Pickett, B.W. \& Nett, T.M. (1974) Reproductive physiology of the stallion. IV. Seasonal changes in the testosterone concentration of peripheral plasma. J. Reprod. Fert. 39, $115-118$.

Berndtson, W.E., Squires, E.L. \& Thompson, D.L., Jr (1983) Spermatogenesis, testicular composition and the concentration of testosterone in the equine testis as influenced by season. Theriogenology 20, 449457 .

Clay, C.M., Squires, E.L., Amann, R.P. \& Pickett, B. (1987) Influences of season and artificial photoperiod on stallions: Testicular size, seminal characteristics and sexual behavior. J. Anim. Sci. 64, 517-525.

Clay, C.M., Squires, E.L., Amann, R.P. \& Nett, T.M. (1988) Influences of season and artificial photoperiod on stallions: luteinizing hormone, follicle stimu- lating hormone and testosterone. J. Anim. Sci. 66, 1246-1255.

Clermont Y. (1972) Kinetics of spermatogenesis in mammals: seminiferous epithelium cycle and spermatagonial renewal. Physiol. Rev. 52, 198-204.

Clermont, Y. \& Morgentaler, H. (1955) Quantitative study of spermatogenesis in the hypophysectomized rat. Endocrinology 57, 369-374.

Cornwell, J.C. (1972) Seasonal variation in stallion semen and puberty in the Quarter Horse colt. M.S. thesis, Louisiana State University.

Curtis, S.K. \& Amann, R.P. (1981) Testicular development and establishment of spermatogenesis in Holstein Bulls. J. Anim. Sci. 53, 1645-1657.

Florcruz, S.V. \& Lapwood, K.R. (1978) A longitudinal study of pubertal development in boars. Int. $J$. Androl. 1, 317-330.

Foster, D.L., Mickelson, I.H., Ryan, K.D., Coon, G.A., Drongowski, R.A. \& Holt, J.A. (1978) Ontogeny of pulsatile luteinizing hormone and testosterone secretion in male lambs. Endocrinology 102, $1137-1142$.

Ganjam, V.K. \& Amann, R.P. (1973) Testosterone and dihydrotestosterone concentrations in the fluid milieu of spermatozoa in the reproductive tract of the bull. Acta endocr., Copenh. 74, 186-200.

Gebauer, M.R., Pickett, B.W. \& Swierstra, E.E. (1974a) Reproductive physiology of the stallion. II. Daily production and output of sperm. J. Anim. Sci. 39, 732-736.

Gebauer, M.R., Pickett, B.W., Voss, J.L. \& Swierstra, E.E. (1974b) Reproductive physiology of the stallion: daily sperm output and testicular measurements. $J$. Am. vet. med. Assoc. 165, 711-713.

Glassneck, H.W. (1978) Histometrische Untersuchungen uber die Entwicklung des Pferdehodens Zwischen 1. und 18. Lebensmonat. D.M.V. dissertation, Tierarztliche Hochschule Hannover.

Hancock, J.L. (1952) The morpholoy of bull spermatozoa. J. exp. Biol. 29, 323-324.

Johnson, L. \& Tatum, M.E. (1988) Sequence of seasonal changes in numbers of Sertoli, Leydig and germ cells 
in adult stallions. Proc. 11th Int. Cong. on Anim. Reprod. \& A.I., Dublin, pp. 373-378.

Johnson, L. \& Thompson, D.L., Jr (1983) Age-related and seasonal variation in the Sertoli cell population, daily sperm production and serum concentrations of follicle-stimulating hormone, luteinizing hormone and testosterone in stallions. Biol. Reprod. 29, 777-783.

Killian, G.J. \& Amann, R.P. (1972) Reproductive capacity of dairy bulls. IX. Changes in reproductive organ weights and semen characteristics of Holstein bulls during the first thirty weeks after puberty. J. Dairy Sci. 55, 1631-1635.

Lewis, L.D. (1982) Feeding and Care of the Horse, p. 226. Lea and Febiger, Philadelphia.

Lunstra, D.D. \& Echternkamp, S.E. (1982) Puberty in beef bulls: acrosome morphology and semen quality in bulls of different breeds. J. Anim. Sci. 55, 638-648.

MacMillan, K.L. \& Hafs, H.D. (1968) Gonadal and extragonadal sperm numbers during reproductive development of Holstein bulls. J. Anim. Sci. 27, 697-700.

McCarthy, M.S., Hafs, H.D. \& Convey, E.M. (1979) Serum hormone changes associated with growth and sexual development in bulls. J. Anim. Sci. 4, $1012-1019$.

Nett, T.M., Holtan, T.W. \& Estergreen, V.L. (1975) Levels of luteinizing hormone, prolactin and oestrogens in the serum of postpartum mares. J. Reprod. Fert., Suppl. 23, 201-206.

Nett, T.M., Pickett, B.W. \& Squires, E.L. (1979) Effects of Equimate (ICI-81008) on levels of LH, FSH and progesterone during the estrous cycle of the mare. $J$. Anim. Sci. 48, 69-75.

Nishikawa, Y. (1959) Studies on Reproduction in Horses, pp. 2-27. Japan Racing Assoc., Tokyo.

Olster, D.H. \& Foster, D.L. (1986) Control of gonadotropin secretion in the male during puberty: a decrease in response to steroid inhibitory feedback in the absence of an increase in steroid independent drive in sheep. Endocrinology 118, 2225-2234.
Pickett, B.W. \& Back, D.G. (1973) Procedures for preparation, collection, evaluation, and insemination of stallion semen. Colo. State Univ. Exp. Stn and Animal Reprod. Lab. Gen. Series Bull. 935, p. 25.

Pickett, B.W., Faulkner, L.C., Seidel, G.E., Jr, Berndtson, W.E. \& Voss, J.L. (1976) Reproductive physiology of the stallion. VI. Seminal and behavioral characteristics. J. Anim. Sci. 43, 617-625.

Pickett, B.W., Squires, E.L. \& McKinnon, A.O. (1987) Procedures for collection, evaluation and utilization of stallion semen for artificial insemination. Colo. State Univ. Anim. Reprod. Lab. Gen. Series Bull. No. 03.

Pickett, B.W., Amann, R.P., McKinnon, A.O., Squires, E.L. \& Voss, J.L. (1989) Management of the stallion for maximum reproductive efficiency, II. Colo. State Univ. Anim. Reprod. Lab. Bull. 05 (In press).

Skinner, J.D. \& Bowen, J. (1968) Puberty in the Welsh Stallion. J. Reprod. Fert. 16, 133-135.

Steel, R.G.D. \& Torrie, J.H. (1980) Principles and Procedures of Statistics: A Biometrical Approach. McGraw-Hill Book Co., New York.

Thompson, D.L., Jr \& Honey, P.G. (1984) Active immunization of prepubertal colts against estrogens: hormonal and testicular responses after puberty. $J$. Anim. Sci. 59, 189-196.

Thompson, D.L., Jr, Pickett, B.W., Squires, E.L.\& Amann, R.P.(1979) Testicular measurements and reproductive characteristics in stallions. J. Reprod. Fert., Suppl. 27, 13--17.

Wesson, J.A. \& Ginther, O.J. (1980) Plasma gonadotropin concentrations in intact female and intact and castrated male prepubertal ponies. Biol. Reprod. 22, 541-549.

Wolf, F.R., Almquist, J.O. \& Hale, E.B. (1965) Prepuberal and puberal characteristics of beef bulls on high nutrient allowance. J. Anim. Sci. 24, 761-773.

Received 30 March 1989 